PERSONAL PRACTICE

\title{
The laryngeal mask airway: potential applications in neonates
}

\author{
D Trevisanuto, M Micaglio, P Ferrarese, V Zanardo
}

Arch Dis Child Fetal Neonatal Ed 2004;89:F485-F489. doi: 10.1136/adc.2003.038430

The laryngeal mask airway is a safe and reliable airway management device. This review describes the insertion techniques, advantages, limitations, and potential applications of the laryngeal mask airway in neonates.

$2.5-5 \mathrm{~kg} .{ }^{11}$ It has been postulated that a smaller size (0.5) could be useful in preterm newborns. However, there are reports of successful use of size 1 in preterm neonates weighing $0.8-1.5 \mathrm{~kg} .{ }^{12-15}$

(2) Fully deflate the cuff as described in the manual, and lubricate the back of the mask tip (for neonates in the labour ward, lubrication may not be necessary, as oral and pharyngeal secretions may reproduce this function).

(3) Press (flatten) the tip of the LMA against the hard palate. During this manoeuvre, the operator should grasp the LMA like a pen with the index finger at the junction between the mask and the distal end of the airway tube.

(4) Gently advance the LMA with one single movement, applying continuous pressure against the palatopharyngeal curvature with the index finger. The vector of the force applied must be directed cranially and not caudally.

(5) Continue pushing the LMA against the soft palate so that the cuff passes along the posterior pharyngeal wall and the tip locates itself in the hypopharynx-that is, it cannot be pushed further inwards.

(6) Inflate the mask to the minimum air volume necessary to establish an adequate seal. The maximum recommended volume for each size is rarely required. Do not hold the shaft of the LMA during cuff inflation, as the shaft may be observed to move outwards during cuff inflation allowing correct positioning.

(7) Connect the proximal end of the airway tube to a device (bag, ventilator) for PPV.

(8) Correct LMA positioning (fig 2) can be evaluated by observing synchronous movements of the chest and by neck auscultation.

The most common problem encountered during this manoeuvre is obstruction at the base of the tongue. In this case, the mask must be removed and the procedure reviewed in all its phases. Failure to follow the recommended insertion technique strictly may result in malposition of the LMA. Specifically, the epiglottis may be "downfolded", the mask lumen may not be correctly aligned with the laryngeal inlet, or the cuff may fold inwards or lie too high in the pharynx. ${ }^{16-18}$

For proper positioning of the LMA in infants the following steps must be followed.

35158, 35158 Padova, Italy; trevo@pediatria.unipd.it

Accepted 4 April 2004

.....................

(1) Use the correct size of LMA for the patient. Size 1 is suitable for neonates weighing
Abbreviations: LMA, laryngeal mask airway; PPV, positive pressure ventilation 


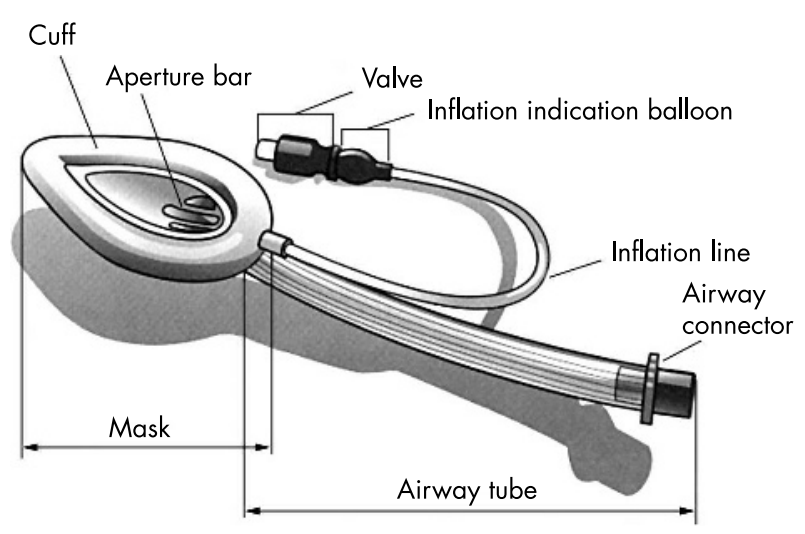

Figure 1 Basic laryngeal mask airway design. Reproduced by permission from Dr A I J Brain. Laryngeal mask instructor manual, 2000. Courtesy of The Laryngeal Mask Company Limited.

After correct insertion and use, the LMA is left in place, until spontaneously ejected by the patient. The overall incidence of complications after removal of the LMA is about $10-13 \%$, including coughing, laryngospasm, retching, breath holding, vomiting, stridor, desaturation, and excessive salivation. ${ }^{19}$ Many of these complications are caused by overinflation of the LMA cuff and inadequate analgesia. A survey of almost 12000 patients of all ages managed with the LMA over a two year period reported only $18(0.15 \%)$ critical incidents related to airway management, and none required intensive care management. ${ }^{20}$

Since its first commercialisation in the United Kingdom in 1988 and in the United States in 1991, the LMA has gained widespread popularity, initially in adult and then in paediatric patients. ${ }^{16-19}$ The American Society of Anaesthesiologists has included the LMA in the algorithm for difficult airway management. ${ }^{21}$

Over the last 10 years, the original prototype, LMA-Classic, which has been used in thousands/millions of patients, has been modified and improved. There are currently five different versions of the LMA, although only the classic model is currently available in a neonatal size. ${ }^{19}{ }^{22-24}$ LMAProSeal is shortly to be made available in paediatric sizes and awaits evaluation (A I J Brain, personal communication).

\section{ADVANTAGES OF THE LMA OVER THE FACE MASK}

Bag-mask ventilation is a technique requiring a high and continuous level of training. Incorrect positioning of the face

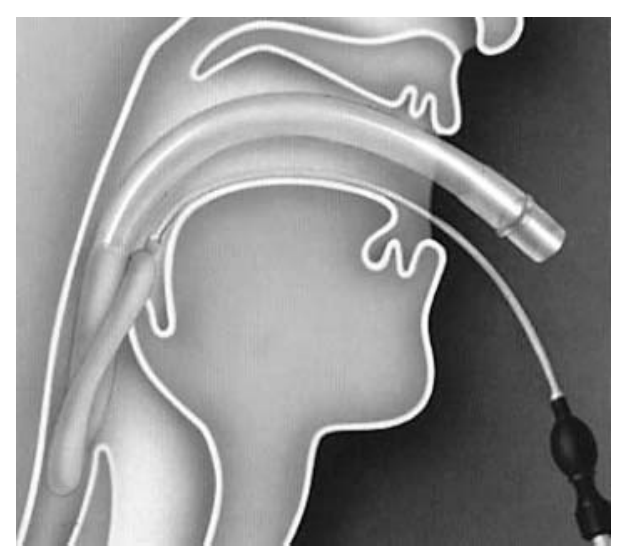

Figure 2 Demonstration of correct anatomical positioning of the laryngeal mask airway cuff around laryngeal inlet. Reproduced by permission from Dr A I J Brain. Laryngeal mask instructor manual, 2000. Courtesy of The Laryngeal Mask Company Limited. mask can cause gas leakage around the rim, and the use of excessive pressure may result in injuries to facial soft tissues. ${ }^{1-6}$ Laboratory studies have shown that most devices commonly used for PPV with bag and mask may be unable to provide adequate tidal volumes during neonatal resuscitation. ${ }^{25}{ }^{26}$ It has also been shown that the efficacy of bag-mask ventilation depends on operator skill. ${ }^{27}$

The LMA offers many advantages over the face mask. ${ }^{13} 1628$ Its use does not require manipulation of the patient's head, neck, and jaw. It also avoids compression of facial nerves. After positioning, the LMA is quite stable and frees the operator's hands for other important tasks. A better airtight seal is achieved with the LMA, providing more effective PPV. ${ }^{929}$ Its insertion technique, stable positioning, and function is not influenced by anatomical factors ${ }^{89}$ that may make face mask ventilation difficult, especially in cases of congenital pathologies such as Pierre-Robin and Treacher Collins syndrome. ${ }^{70}$ Less skill is required to achieve and maintain effective PPV with the LMA compared with the face mask. ${ }^{29}$ In a meta-analysis including 52 randomised prospective trials, the advantages of the LMA over the face mask included: easier placement by inexperienced personnel; improved oxygen saturation; less hand fatigue; improved operating conditions during minor paediatric otological surgery. ${ }^{31}$

It has been shown that the incidence of hypoxia is lower in infants with the use of the LMA than with the face mask. ${ }^{32}$ However, a study on 49 anaesthetised infants aged less than 1 year reported a higher incidence of complications with the LMA $(55.5 \%)$ than with the face mask $(22.7 \%) .^{33}$ These airway complications occurred more often during the intraoperative phase and emergence (13 out of 15) than during the time of LMA insertion (two out of 15). The most important finding was the incidence of intraoperative airway obstruction. An explanation may be the use of an inappropriate size of LMA. ${ }^{34}$ In a prospective survey of LMA use in 1400 infants and children, the overall problem rate was $11.5 \%$, and no major morbidity was associated with the use of the device. ${ }^{35}$

\section{ADVANTAGES OF THE LMA OVER ENDOTRACHEAL INTUBATION}

Laryngoscopy and tracheal intubation are often associated with a number of adverse effects such as local trauma, the stress-response reflex, and malpositioning of the tracheal tube in the oesophagus or in the bronchial tree. ${ }^{36}$ These manoeuvres may also cause hypertension and cyanosis of the patient. ${ }^{37}$

The LMA avoids laryngoscopy and all of its related adverse effects; it is also less invasive with respect to the respiratory tract. In comparison with the endotracheal tube, the patient is subjected to a lower haemodynamic stress response during LMA positioning and removal. ${ }^{37}{ }^{38}$ This could theoretically reduce the incidence of cerebral haemorrhage in neonates. In addition, tracheal oedema, which may be caused by tracheal intubation, is avoided by using the LMA. ${ }^{39}$

Its use may be life saving in patients with malformations of the upper airway when tracheal intubation and mask ventilation fail. ${ }^{5-7} 30$

Whereas successful intubation may require more than one attempt, the LMA is easily inserted by non-anaesthetist personnel. ${ }^{40}$ LMA insertion does not require the use of neuromuscular blocking agents, further diminishing pharmacological risk in neonates.

In summary, the advantages of the LMA over the tracheal tube include: increased speed and ease of placement by anaesthetists, non-anaesthetist medical personnel, and trained non-medical personnel; improved haemodyamic stability during insertion; minimal increase in intraocular 
Table 1 Evaluation of laryngeal mask airway for neonatal resuscitation in three studies

\begin{tabular}{|c|c|c|c|}
\hline & Gandini \& Brimacombe ${ }^{15}$ & Paterson ef $a f^{\mu 2}$ & Trevisanuto ef $a f^{43}$ \\
\hline Study design & Observational, prospective & Observational, prospective & Observational, retrospective \\
\hline Study period & 2 months & 5 years & 12 months \\
\hline No of patients & 21 & $104(29+75)^{*}$ & 95 \\
\hline No of operators & 3 & 1 & 10 \\
\hline Training (uses/operator) & 8 & 5 & 10 \\
\hline Gestational age (weeks) & $38(2)$ & $37(34-42), 32(28-37)$ & $39(29-42)$ \\
\hline Birth weight $(\mathrm{kg})$ & $3.3(0.6)$ & $3.7(2.7-4.7), 2.0(1.2-2.4)$ & $3.1(0.9-4.9)$ \\
\hline Caesarean section (\%) & NA & 78 & 45 \\
\hline Apgar score (5 min) & $8(5-10)$ & $9(7-10), 8(6-10)$ & $9(5-10)$ \\
\hline Indication for LMA use & Apnoea $/ \mathrm{HR}<100 / \mathrm{min}$ & Apnoea/HR $<100 / \mathrm{min}$ & Apnoea $/ \mathrm{HR}<100 / \mathrm{min}$ \\
\hline Insertion attempts (1/2) & $21 / 0$ & $104 / 0$ & $95 / 0$ \\
\hline Time for LMA insertion (seconds) & $8.6(1.4)$ & NA & NA \\
\hline Duration of LMA placement (seconds) & 80 (61) (PPV) 55 (28) (CPAP) & $42(19-408)$ & $74(32-904)$ \\
\hline Efficacy $(\%)$ & 95 & 99 & 99 \\
\hline $\begin{array}{l}\text { Time to reach adequate oxygenation } \\
\text { (seconds) }\end{array}$ & $<60$ & 19 & $<30$ \\
\hline Late intubation & $1(4.7 \%)$ & $6(5.7 \%)$ & $5(5.2 \%)$ \\
\hline Audible peak pressure $\left(\mathrm{cm} \mathrm{H}_{2} \mathrm{O}\right)$ & $22(3)$ & $22(15-32), 24(16-36)$ & NA \\
\hline Peak pressure obtained $\left(\mathrm{cm} \mathrm{H}_{2} \mathrm{O}\right)$ & $37(3)$ & NA & NA \\
\hline Admission to NICU (\%) & 15 & NA & 21 \\
\hline \multicolumn{4}{|l|}{ No of complications } \\
\hline Pneumothorax & 1 & 0 & 1 \\
\hline Gastric insufflation & 0 & 0 & 0 \\
\hline
\end{tabular}

Unless otherwise indicated, data are expressed as mean (SD) or median (range).

*Data are for two groups of patients (low birthweight and term infants respectively).

CPAP, Continuous positive airway pressure; HR, heart rate; LMA, laryngeal mask airway; NA, not available; NICU, neonatal intensive care unit; PPV, positive

pressure ventilation.

pressure after insertion; reduced anaesthetic requirements for airway tolerance and lower incidence of coughing during emergence; improved oxygen saturation during emergence; a lower incidence of sore throat in adults. ${ }^{31}$

\section{DISADVANTAGES OF THE LMA}

Potential disadvantages are mainly the following. ${ }^{13}{ }^{17} 41$

(1) Gastric insufflation and aspiration. The LMA does not separate the respiratory and alimentary tracts, thus exposing the patient to the risk of aspiration and gastric insufflation during PPV; this fact may limit the efficacy of ventilation. Meticulous attention to the insertion and fixation of the LMA and avoidance of excessive positive pressure may eliminate this, as has been reported in adult studies. ${ }^{18} 20$

(2) Inadequate alveolar ventilation. The LMA cuff forms a low pressure seal against the larynx. The maximum seal pressure is $20-25 \mathrm{~cm} \mathrm{H}_{2} \mathrm{O} .{ }^{8}{ }^{911}$ It is known that, during the first breaths at birth, or for some specific pulmonary diseases, pressures required to achieve effective ventilation can be higher, and in these cases the LMA may be ineffective. $^{156}$ The recently introduced LMA-ProSeal, now available for paediatric use, may alleviate this problem.

(3) Impossibility of suctioning the airway or administering drugs endotracheally. Depressed neonates with meconium aspiration syndrome require tracheal intubation and suctioning. ${ }^{156}$ The latter cannot be performed by means of the LMA, as the passage of suctioning tubes may be partially or totally impaired or cause laryngeal spasm. Administering of drugs through the LMA may also be not possible. ${ }^{13} 17$

\section{POTENTIAL APPLICATIONS IN NEONATES Resuscitation}

Official Scientific Societies such as the International Liaison Committee on Resuscitation, American Academy of Pediatrics, and American Heart Association have stated that the LMA may be useful when face mask and endotracheal intubation fail, although they do not recommend its routine use because of the lack of clear scientific evidence (Class Indeterminate). ${ }^{56}$

Studies on the efficacy of ventilation by medical and paramedical personnel in neonatal training models have shown that the LMA allows a patent airway to be obtained in a shorter time than the endotracheal tube. They also show that the incidence of failure is lower with the LMA. ${ }^{40}$

The use of the LMA for neonatal resuscitation has been reported in three case series. ${ }^{15} 4243$ Altogether 220 neonates were included in these three observational studies (table 1). The most important results are as follows.

(a) Baseline characteristics. The clinical characteristics of the patients were similar among the three studies, even though a subgroup of low birthweight infants was considered in the study of Gandini and Brimacombe. ${ }^{15} \mathrm{~A}$ low number of operators was involved in two of the three studies. ${ }^{15} 42$

(b) The ease of use of the LMA. In the three studies, training included use of the LMA only a few times (5-10 per operator), and, in all the neonates, the LMA was properly positioned at the first attempt. The time required for LMA insertion reported in the study of Paterson et al, ${ }^{42}$ was very short (8.6 (1.4) seconds).

(c) Efficacy of the LMA. An effective PPV was obtained in most of the treated patients (range 95-99\%); in particular, adequate oxygenation was obtained in a short time (19-60 seconds) in all the studies.

(d) Technical aspects. Two studies reported the audible peak pressure $\left(22-24 \mathrm{~cm} \mathrm{H}_{2} \mathrm{O}\right),{ }^{15}{ }^{42}$ and one registered the peak pressure obtained $\left(37\right.$ (3) $\left.\mathrm{cm} \mathrm{H}_{2} \mathrm{O}\right) .{ }^{42}$ These high levels may be explained by the fact that the operators "held the LMA in situ by gently applying a constant pressure on the airway tube". ${ }^{42}$ The mean/ median duration of the LMA placement was less than two minutes. ${ }^{15} 42$

(e) Outcome. Fifteen and twenty one percent of the resuscitated patients were admitted to the neonatal intensive care unit in the studies of Paterson et $a l^{42}$ and 
Trevisanuto et al ${ }^{43}$ respectively. ${ }^{42}{ }^{43}$ Two patients developed pneumothorax which, however, was not clearly linked to the LMA use. ${ }^{42}{ }^{43}$ No study reported gastric insufflation in the treated patients.

In a recent regional survey, the LMA was used in 101 out of $1526(6.6 \%)$ neonates needing PPV at birth. ${ }^{44}$ Among them, however, 95 were from a single centre, indicating that there is still little awareness of this treatment modality. In addition, the LMA availability and perceived value were different between anaesthesiologists and paediatricians. ${ }^{44}$

\section{Neonatal intensive care}

Some authors have suggested that the LMA may have a role in some emergency situations. Recently, we studied the feasibility and practicality of administering surfactant using the LMA in eight preterm infants with respiratory distress syndrome. The mean arterial to alveolar oxygen tension ratio significantly increased (50\%) from before to three hours after the surfactant therapy. ${ }^{45}$ These data indicate that the LMA can be used as a conduit to obtain rapid and non-invasive access to the trachea of preterm infants to administer surfactant. This would encourage the policy of "minimal handling" and could avoid respiratory and extra-respiratory complications such as stress and intraventricular haemorrhage associated with tracheal intubation.

The LMA has also been used in neonates affected by malformations of the upper airway in emergency situations and during laryngoscopy and bronchial endoscopy. In particular, the LMA has proved useful in the intubation manoeuvre in this group of patients. ${ }^{76} 47$

Neonates affected by multiple congenital arthrogryposis and micrognathia, ${ }^{48}$ and patients with bronchopulmonary dysplasia $^{14}$ undergoing cryotherapy for retinopathy of the prematurity have been ventilated with the LMA.

The use of the LMA for long periods, described in adult patients, ${ }^{49}$ has been recently reported in a 10 day old neonate with airway obstruction and severe Treacher Collins syndrome..$^{50}$ Theoretically, the LMA may have a role in the weaning of patients with good pulmonary compliance.

The efficacy of the LMA has also been reported in a case in which ventilation of a neonate with face mask had failed during helicopter transportation. ${ }^{51}$

\section{CONCLUSIONS}

Since its introduction into clinical practice, the LMA has gained increasing popularity for resuscitation of both adult and paediatric patients. Some authorities have added the use of this device to their guidelines, at least as an aid in cases of difficult airway management or failure of conventional manoeuvres.

There are currently no randomised, controlled trials on the use of the LMA during neonatal resuscitation. Although this device cannot be considered a substitute for the tracheal tube, it could, at least theoretically, play an ancillary role, particularly in situations where assistance to the asphyxiated neonate is offered by paramedical staff or doctors who, because of the rarity of the event, may have difficulty maintaining a high level of skill. ${ }^{52}$

Further studies are necessary to compare the advantages and limits of the LMA with conventional methods currently used in neonatal resuscitation and intensive care. ${ }^{53}$

Features of more recent LMA versions appear to overcome the limits of the classic device, thus producing optimal conditions for use in neonatal patients.

\section{ACKNOWLEDGEMENTS}

We thank Dr Chandy Verghese and Dr Archie I J Brain, Royal Berkshire Hospital, Reading, UK, for valuable comments on the manuscript.

\section{Authors' affiliations}

D Trevisanuto, P Ferrarese, V Zanardo, Department of Paediatrics, University Hospital of Padua, Padua, Italy

M Micaglio, Department of Pharmacology and Anaesthesiology, E Meneghetti Section of Anaesthesiology and Intensive Care, University Hospital of Padua

\section{REFERENCES}

1 Kattwinkel J, ed. Textbook of neonatal resuscitation. 4th ed. American Academy of Pediatrics and American Heart Association, 2000.

2 Trevisanuto D, Zanardo V, Zacchello F. Neonatal resuscitation: certainty and shadows of doubt. Ital J Pediatr $2001 ; 27: 744-9$

3 Ginsberg HG, Goldsmith JP. Controversies in neonatal resuscitation. Pediatr Clin North Am 1998;25:1-15.

4 Trevisanuto D, Zacchello F, eds. Cardiopulmunary resuscitation in the newborn. 16th Postgraduate course in critical care medicine, A.P.I.C.E. Trieste. Italy: Springer, November 16-20, 2001:1165-74.

5 International guidelines for neonatal resuscitation: an excerpt from the guidelines 2000 for cardiopulmonary resuscitation and emergency cardiovascular care: international consensus on science. Pediatrics 2000;106: 1-16.

6 Kattwinkel J, Niermeyer S, Nadkarni V, et al. ILCOR advisory statement: resuscitation of the newly born infant. Pediatrics 1999;103:e56.

7 Behar PM, Todd NW. Resuscitation of the newborn with airway compromise. Clin Perinatol 1999;26:717-32.

8 Brain Al. The laryngeal mask: a new concept in airway management. Br J Anaesth 1983;55:801-5.

9 Brimacombe J, Berry A. The laryngeal mask airway: anatomical and physiological implications. Acta Anaesthesiol Scand 1996;40:201-9.

10 Soh CR, Ng AS. Laryngeal maskairway insertion in paediatric anesthesia: comparison between the reverse and standard technique. Anaesth Intensive Care $2001 ; 29: 515-9$

11 Brimacombe J, Brain Al, Berry A. The laryngeal mask airway: review and practical guide. Philadelphia: WB Saunders, 1997.

12 Brimacombe J. Airway rescue and drug delivery in an $800 \mathrm{~g}$ neonate with the laryngeal mask airway. Paediatr Anaesth 1999;9:178.

13 Berry AM, Brimacombe J, Verghese C. The laryngeal mask airway in emergency medicine, neonatal resuscitation, and intensive care medicine. Emerg Med 1998;1436:91-109.

14 Lonnqvist PA. Successful use of laryngeal mask airway in low-weight expremature infants with bronchopulmonary dysplasia undergoing cryotherapy for retinopathy of the premature. Anesthesiology 1995;83:422-4.

15 Gandini D, Brimacombe JR. Neonatal resuscitation with the laryngeal mask airway in normal and low birth weight infants. Anesth Analg 1999;89:642-3.

16 Pennant JH, White PF. The laryngeal mask airway. Its uses in anesthesiology. Anesthesiology 1993;79:144-63.

17 Brimacombe JR, Berry AM, White PF. The laryngeal mask airway: limitations and controversies. Int Anesthesiol Clin 1998;36:155-82.

18 Schmiesing CA, Brock-Utne JG. An airway management device: the laryngeal mask airway: a review. J Intensive Care Med 1998;13:32-43.

19 Boehringer LA, Bennie RE. Laryngeal mask airway and the pediatric patient. Int Anaesthesiol Clin 1998;36:45-60.

20 Verghese C, Brimacombe JR. Survey of laryngeal mask airway usage in 11,910 patients: safety and efficacy for conventional and nonconventional usage. Anesth Analg 1996;82:129-33.

21 American Society of Anesthesiologists Task Force on Management of the difficult airway. Practice guidelines for management of the difficult airway. Anesthesiology 1993;78:597-602.

22 Brain AIJ, Vergese C, Addy EV. The intubating laryngeal mask. I. Development of a new device for intubation of the trachea. Br J Anaesth 1997;79:699-703.

23 Brain AlJ, Vergese C, Addy EV, et al. The intubating laryngeal mask II: a preliminary clinical report of a new means of intubating the trachea. BrJ Anaesth 1997;79:704-9.

24 Brain Al, Vergese C, Strube PJ, et al. The LMA 'ProSeal': a laryngeal mask with an oesophageal vent. BrJ Anaesth 2000;84:650-4.

25 Jesudian MC, Harrison RR, Keenan RL, Maull KI. Bag-valve-mask ventilation; two rescuers are better than one: preliminary report. Crit Care Med $1985 ; 13: 122-3$.

26 Milner AD, Vyas $\mathrm{H}$, Hopkin IE. Efficacy of facemask resuscitation at birth. BMJ 1984;289:1563-5.

27 Finer NN, Rich W, Craft A, et al. Comparison of methods of bag and mask ventilation for neonatal resuscitation. Resuscitation 2001;49:299-305.

28 Brimacombe J, Gandini D. The laryngeal mask airway: potential application in neonatal health care. J Obstet Gynecol Neonatal Nurs 1997;26:171-8.

29 Martin PD, Cyna AM, Hunter WAH, et al. Training nursing staff in airway management for resuscitation: a clinical comparison of the facemask and laryngeal mask. Anaesthesia 1993;18:33-7.

30 Markakis DA, Sayson SC, Schreiner MS. Insertion of the laryngeal mask airway in awake infants with the Robin sequence. Anasth Analg 1992;75:822-4.

31 Brimacombe J. The advantages of the LMA over the tracheal tube or facemask: a meta-analysis. Can J Anaesth 1995;42:1017-23.

32 Watcha MF, Garner FT, White PF, et al. Laryngeal mask airway vs facemask and Guedel airway during pediatric myringotomy. Arch Otolaryngol Head Neck Surg 1994;120:877-80. 
33 Harnett M, Kinirorns B, Heffernan A, et al. Airway complications in infants: comparison of laryngeal mask airway and the facemask-oral airway. Can J Anaesth 2000;47:315-18.

34 Brain Al. Size matters! Can J Anaesth 2000:47:1262-3.

35 Lopez-Gil M, Brimacombe J, Alvarez M. Safety and efficacy of the laryngeal mask airway. A prospective survey of 1400 children. Anaesthesia 1996;51:969-72.

36 Asai T, Koga K, Vaughn RS. Respiratory complications associated with tracheal intubation and extubation. Br J Anaesth 1998;80:767-75.

37 Fujii Y, Tanaka H, Toyooka H. Circulatory response to laryngeal mask airway insertion or tracheal intubation in normotensive and hypertensive patients. Can J Anaesth 1995;42:32-6.

38 Fujii $Y$, Saitoh $Y$, Tanaka H, et al. Cardiovascular responses to tracheal extubation or LMA removal. Can J Anaesth 1998;45:178-81.

39 Tanaka A, Isono S, Ishikawa $\mathrm{T}$, et al. Laryngeal resistance before and after minor surgery. Anesthesiology 2003;99:252-8.

40 Lavies NG. Use of the laryngeal mask airway in neonatal resuscitation. Anaesthesia 1993:48:352.

41 Brimacombe Gandini JR D. Resuscitation of neonates with the laryngeal mask: a caution. Pediatrics 1995;95:453-4.

42 Paterson SJ, Byrne PJ, Molesky MG, et al. Neonatal resuscitation using the laryngeal mask airway. Anesthesiology 1994;80:1248-53.

43 Trevisanuto $D$, Micaglio $M$, Pitton $M$, et al. Laryngeal mask airway: is management of neonates requiring positive pressure ventilation at birth changing? Resuscitation 2004;62:151-7.

44 Trevisanuto D, Ferrarese $P$, Zanardo $V$, et al. Laryngeal mask airway in neonatal resuscitation: a survey of current practice and perceived role by anesthsiologists and pediatricians. Resuscitation 2004;60:291-6.
45 Trevisanuto D, Grazzina N, Micaglio M, et al. Laryngeal mask airway as a delivery channel for administration of surfactant in preterm infants with RDS. Pediatric Academic Societies' Annual Meeting. San Francisco, California, 1-4 May 2004. Pediatr Res 2004:55:515A

46 Ellis DS, Potluri PK, O'Flaherty JE, et al. Difficult airway management in the neonate: a simple method of intubating through a laryngeal mask airway. Pediatric Anaesthesia 1999:9:460-2.

47 Wheatley RS, Stainthorp SF. Intubation of one-day-old baby with Pierre-Robin syndrome via a laryngeal mask. Anaesthesia 1994;49:733.

48 Nguyen NH, Morvant EM, Mayhew JF. Anesthetic management for patients with arthrgryposis multiplex congenita and severe micrognathia: case reports. J Clin Anesth 2000;12:227-230.

49 Arosio EM, Conci F. Use of the laryngeal mask airway for respiratory distress in intensive care unit. Anaesthesia 1995;50:635-6.

50 Bucx MJ, Grolman W, Kruisinga FH, et al. The prolonged use of the laryngeal mask airway in a neonate with airway obstruction and Treacher Collins syndrome. Pediatr Anaesth 2003;13:530-3.

51 Brimacombe J, De Maio B. Emergency use of the laryngeal mask airway during helicopter transfer of a neonate. J Clin Anesth 1995;7:689-90.

52 Anonymous. Standard and guidelines for cardiopulmonary resuscitation (CPR) and emergency cardiac care (ECC). Part VI. Neonatal advanced life support. JAMA 1986;255:2969-73.

53 Grein AJ, Weiner GM. Laryngeal mask airway versus bag-mask ventilation or endotracheal intubation for neonatal resuscitation [protocol]. Cochrane Library Document, 2002. 